\title{
Chapter 16 \\ The Contribution of Citizen Scientists \\ to the Monitoring of Marine Litter
}

\author{
Valeria Hidalgo-Ruz and Martin Thiel
}

\begin{abstract}
Citizen science projects are based on volunteer participation of untrained citizens who contribute information, data and samples to scientific studies. Herein we provide an overview of marine litter studies that have been supported by citizen scientists $(n=40)$ and compare these studies with selected studies conducted by professional scientists $(n=40)$. Citizen science studies have mainly focused on the distribution and composition of marine litter in the intertidal zone. Studies extended over regional, national and international scales, with time periods generally extending from less than one year to two years. Professional studies have also examined the distribution and composition of marine litter, but from intertidal, subtidal and pelagic zones, with some focusing exclusively on microplastics. These studies have been conducted over local, regional and international scales, usually for less than one year each. Both citizen science and professional studies on marine litter have been conducted mainly in the northern hemisphere, revealing a lack of information available on coastal regions of the southern hemisphere. A main concern of citizen science studies is the reliability of the collected information, which is why many studies include steps to ensure data quality, such as preparation of clear protocols, training of volunteers, in situ supervision by professional scientists, and revision of samples and data. The results of this comparative review confirm that citizen science can be a useful approach to increase the available information on marine litter sources, distribution and ecological impacts. Future studies should strive to incorporate
\end{abstract}

\footnotetext{
V. Hidalgo-Ruz $\cdot$ M. Thiel $(\bowtie)$

Facultad Ciencias del Mar, Universidad Católica del Norte,

Larrondo 1281, Coquimbo, Chile

e-mail: thiel@ucn.cl

M. Thiel

Millennium Nucleus Ecology and Sustainable Management of Oceanic Island (ESMOI), Coquimbo, Chile

M. Thiel

Centro de Estudios Avanzados en Zonas Áridas (CEAZA), Coquimbo, Chile
} 
additional citizen scientists who frequent marine environments, for instance, divers and sailors, to improve our understanding of marine litter dynamics.

Keywords Citizen science - Marine litter - Professional studies - Volunteers • Data quality

\subsection{Introduction}

Large quantities of anthropogenic litter reach the marine environment, where they spread throughout all oceans and persist for many years (Derraik 2002; Barnes et al. 2009; Ryan et al. 2009; Eriksen et al. 2014). The accumulation of litter causes diverse impacts on marine biota, such as entanglement (Laist 1997; Moore et al. 2009), ingestion (e.g. van Franeker et al. 2011; Carson 2013; Cole et al. 2013), and dispersal of alien species (Barnes 2002; Masó et al. 2003; Kiessling et al. 2015). The extensive spreading of marine litter, even to the most remote regions of the world's oceans, makes litter distribution and abundance surveys difficult and time consuming (Ryan et al. 2009; Eriksen et al. 2014). Coastal regions, where a large fraction of marine litter is deposited, receive visits from a wide range of people, including, but not limited to, tourists, fishermen, and schoolchildren. Such coastal users have been recruited to support scientific beach surveys to quantify marine litter worldwide (e.g. Ogata et al. 2009; Ribic et al. 2010). These volunteers (here termed "citizen scientists") (Bonney et al. 2009) have participated in the collection, analysis and interpretation of data in a wide range of studies, determining litter distribution and abundance in the marine environment (Lindborg et al. 2012; Smith and Edgar 2014; Thiel et al. 2014).

Herein we provide a review of marine litter studies that have been supported by citizen scientists in order to evaluate their contribution to current knowledge on marine litter distribution, abundance, and interaction with marine biota. In particular, we compare the type and quality of data collected in these citizen science studies with those collected by professional scientists (scientists that have received a formal scientific education). Based on the results of this comparison, we offer recommendations for future marine litter surveys that are supported by citizen scientists.

\subsection{Marine Litter Studies Supported by Citizen Scientists}

People from a wide range of educational backgrounds have supported scientific studies on marine litter. Their interest to participate in this kind of investigation may vary depending on their own personal motivation, which may include being part of an environmental organization (e.g. marine conservation NGO, girl \& boy scouts) or an educational project within a school (Fig. 16.1). For example, beach cleanup 
Fig. 16.1 Examples of citizen scientists participating in studies on marine litter
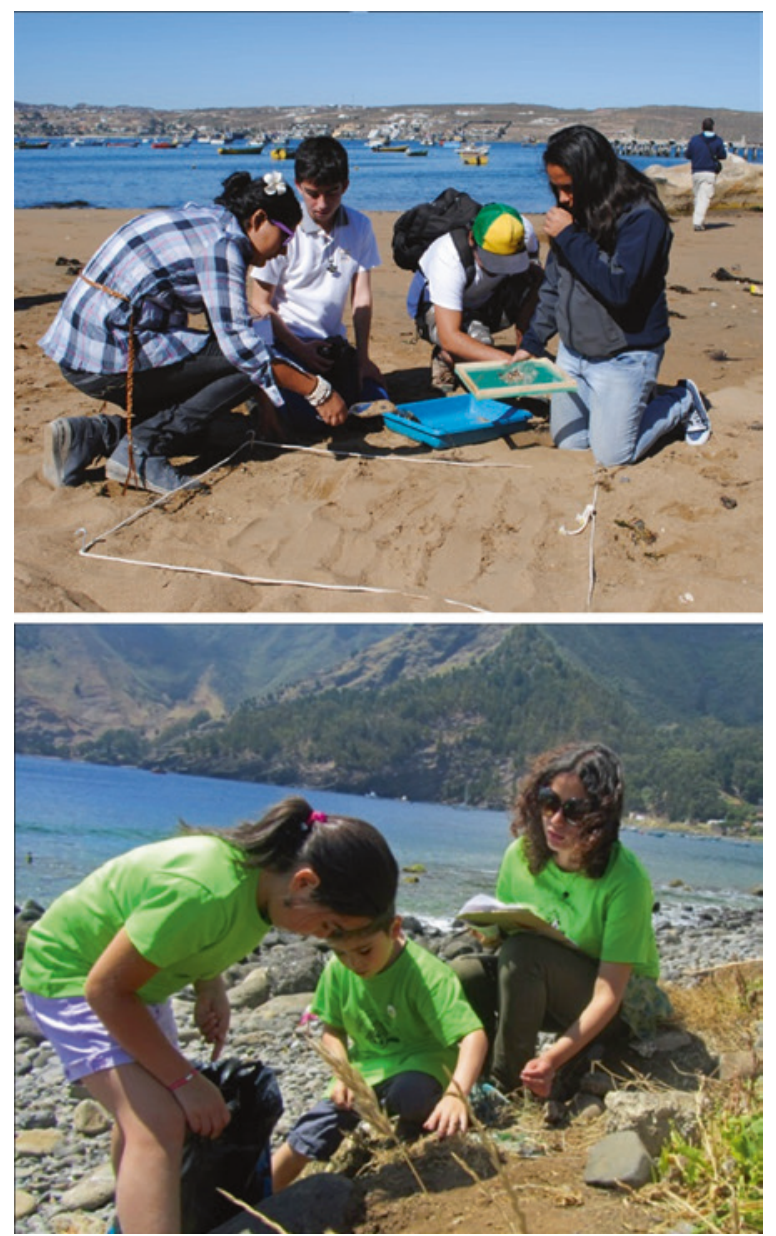

campaigns are conducted in many countries, and can be a source of marine litter information supported by citizen scientists (e.g. Ribic 1998; Martin 2013).

For this review, marine litter studies were identified by searching the ISI Web of Knowledge and Google Scholar databases for papers using the keywords "citizen science" or "volunteer" with "marine litter", "marine debris" or "plastic debris". We thoroughly scanned the literature, identifying all studies in which volunteers had participated in sampling and/or sample processing. We only selected studies with a main focus on marine litter; studies which coincidentally also report interactions of litter with marine biota were not considered, unless these explicitly focused on litter aspects, such as plastic ingestion and entanglement by seabirds and marine mammals (Moore et al. 2009; van Franeker et al. 2011). At the time of writing, 40 marine litter studies were identified, which were based entirely or partly on data or samples contributed by citizen scientists (Appendix 1). 
We also selected 40 peer-reviewed articles that were exclusively conducted by professional scientists, in order to compare those with and evaluate the importance, scope and quality of citizen-science studies. For the purpose of this review, we only included the most cited papers (according to ISI Web of Knowledge and Google Scholar databases) that have been published during the past 10 years (2004-2014). Keywords used to identify these studies were "marine litter", "marine debris", "plastic debris" and "beach survey". Review articles were not considered for this comparison between citizen science and professional studies (see Appendix 1 for the complete list of selected studies).

\subsection{Comparison of Citizen Science and Professional Science Studies on Marine Litter}

\subsubsection{Research Topic}

Research on marine litter has focused on six major topics: (1) Distribution and composition of marine litter, (2) interaction with marine biota, (3) toxic effects, (4) horizontal and vertical transport, (5) social aspects and (6) degradation of marine plastic litter. The majority of citizen science studies $(68 \%)$ examined the spatial distribution and composition of marine litter (Table 16.1). In these cases, citizens participated in beach cleanup activities or beach surveys of marine litter (e.g. Gregory 1991; Storrier et al. 2007), plastic beverage containers (Józwiak 2005) and small plastic debris (Hidalgo-Ruz and Thiel 2013). Apart from one study conducted by divers in subtidal environments (Smith and Edgar 2014), the intertidal zone was the only sampling zone.

One citizen-science study also covered the open ocean via a drifter experiment to investigate the pathways of litter from island areas in Hawaii; citizen scientists reported drifters that had stranded on local shores (Carson et al. 2013).

In most cases, data were registered on datasheets provided by an organization, but one study also created a smartphone application, which was used by personal phones and iPods (Martin 2013). Interaction of marine litter with biota was the second most common topic addressed by citizen science studies, but given the overwhelming proportion of studies on the distribution and composition of litter (68\%), this topic represented only $18 \%$ of all studies (Table 16.1). These studies

Table 16.1 Comparison of research topics on marine litter, conducted by citizen scientists $(\mathrm{N}=40)$ and professional scientists $(\mathrm{N}=40)$

\begin{tabular}{|c|c|c|c|c|}
\hline \multirow[t]{2}{*}{ Topic } & \multicolumn{4}{|c|}{ Citizen science Professional } \\
\hline & No. & $\%$ & No. & $\%$ \\
\hline Distribution and composition & 27 & 67.5 & 18 & 45 \\
\hline Interaction with biota & 7 & 17.5 & 14 & 35 \\
\hline Toxic effects & 4 & 10.0 & 3 & 7.5 \\
\hline Transport & 1 & 2.5 & 3 & 7.5 \\
\hline Social aspects & 1 & 2.5 & 1 & 2.5 \\
\hline Degradation & 0 & 0 & 1 & 2.5 \\
\hline
\end{tabular}


focused on specific animal groups, mostly vertebrates: seabirds (van Franeker et al. 2011; Lindborg et al. 2012), marine mammals (Moore et al. 2009), fish (Carson 2013) and sea turtles (Bjorndal et al. 1994). For example, citizen scientists supported cleanups of derelict crab traps and quantified the species entangled by ghost fishing activity (Anderson and Alford 2014), or information on species affected by marine litter was documented on an interactive website (Hong et al. 2013). Other aspects of marine litter were examined in $15 \%$ of all citizen science studies (Table 16.1). Persistent organic pollutants were determined in beached plastic pellets, which were collected by citizens (Ogata et al. 2009; Hirai et al. 2011; Heskett et al. 2012). Transport of marine litter was studied to determine the factors driving marine debris deposition on Hawaiian beaches (Morishige et al. 2007; Carson et al. 2013). A social study examined the behavior, education and preference of the general public to reduce littering on beaches (Eastman et al. 2013). Degradation of marine litter was not addressed by citizen scientists.

A large portion of professional studies was also based on the distribution and composition of marine litter (45\% of all studies) (Table 16.1). These studies examined beach litter from the intertidal zone $(\mathrm{n}=11)$ (e.g. McDermid and McMullen 2004; Claessens et al. 2011), seafloor debris from the subtidal zone $(n=4)$ (e.g. Katsanevakis and Katsarou 2004), and pelagic plastic litter from the open ocean $(n=6)$ (Lattin et al. 2004; Pichel et al. 2007). In contrast to citizen science studies, a considerable number of the professional studies focused exclusively on microplastics $(\mathrm{n}=11)$ (e.g. Thompson et al. 2004; Ng and Obbard 2006; Browne et al. 2010). This difference is likely due to the advanced techniques required for proper identification of microplastics (especially the smaller fraction of microplastics, $1 \mu \mathrm{m}-1 \mathrm{~mm}$; Löder and Gerdts 2015), which is unfeasible in citizen science studies (Hidalgo-Ruz and Thiel 2013). The interaction of marine litter with biota was addressed by a high proportion of studies (35\% of all studies) (Table 16.1). These studies focused mainly on plastic ingestion by both invertebrates and vertebrates (e.g. Graham and Thompson 2009; Boerger et al. 2010), but also on entanglement of pinnipeds in marine litter (Page et al. 2004; Boren et al. 2006), and on the impact of lost fishing gear on coral reefs (Chiappone et al. 2005). Toxic effects, transport, social aspects and degradation of marine litter were examined by $20 \%$ of the professional studies (Table 16.1). These focused on the quantification of persistent organic pollutants (POP's) in plastics (Rios et al. 2007, 2010; Teuten et al. 2007), the temporal variability and dynamics of marine debris at the sea surface (e.g. Martinez et al. 2009; Law et al. 2010), the socio-economic characteristics of beach users and littering (Santos et al. 2005), and the relationship between composition, surface texture, and degradation of plastics (Corcoran et al. 2009).

\subsubsection{Spatial Scale}

Considering that marine litter is a global issue, the collection of data over extensive spatial scales is particularly important (Galgani et al. 2015). Professional research can 
address this issue, but requires a work-intensive sampling effort or the use of expensive equipment, such as buoys, aircraft, submersible vehicles and satellites (e.g. Pichel et al. 2007; Maximenko et al. 2012). These types of sophisticated surveys might be too expensive for citizen science projects, but with a reasonable budget, citizen science offers the opportunity to establish extensive networks of sampling stations on the ground. Citizen science studies have been conducted on the local (one sampling site), regional (several sampling sites), national and even international scale (Table 16.2). The more extensive citizen science studies were conducted by "The International Pellet Watch" project (see Ogata et al. 2009; Hirai et al. 2011; Heskett et al. 2012), in which volunteers from 17 countries have collected pellets from local beaches and sent them to Tokyo for laboratory analyses. This project has monitored the pollution status of persistent organic pollutants in the oceans since 2005, extending their sampling locations to several new places (Fig. 16.2).

In contrast, professional studies have been conducted relatively homogeneously over all spatial scales, with the exception of national surveys, which only represented two (5\%) of all professional studies (Table 16.2). Examples of local studies include Corcoran et al. (2009) on plastic degradation on Kauai, Hawaii, Graham and Thompson (2009) on the ingestion of plastics by sea cucumbers, and

Table 16.2 Comparison of the spatial scale of citizen science $(\mathrm{N}=40)$, and professional studies $(\mathrm{N}=40)$

\begin{tabular}{l|l|l|l|l}
\hline \multirow{2}{*}{ Spatial scale } & \multicolumn{2}{l|}{ Citizen science } & Professional & \\
\cline { 2 - 5 } & No. & $\%$ & No. & $\%$ \\
\hline Local & 12 & 30 & 16 & 40 \\
\hline Regional & 14 & 35 & 9 & 22.5 \\
\hline National & 8 & 20 & 2 & 5.0 \\
\hline International & 6 & 15 & 13 & 32.5 \\
\hline
\end{tabular}

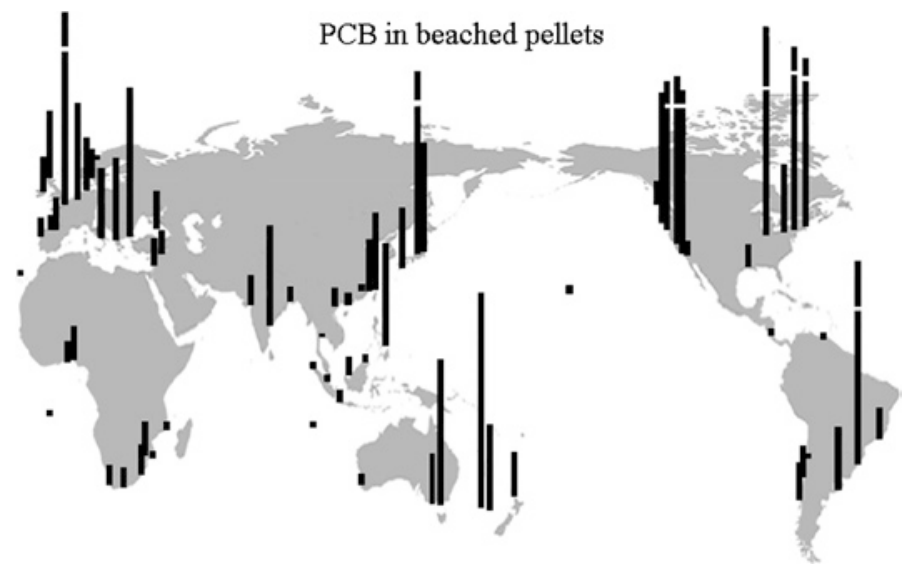

Fig. 16.2 PCB concentration on beached pellets from the volunteer-based global monitoring program "International Pellet Watch". Figure modified from: http://www.pelletwatch.org/ (access: July 2014) 
Santos et al. (2005) on the relationship between beach users and litter generation at Cassino Beach, Rio Grande City, Brazil. Regional research examples are from Costa et al. (2010) on the distribution and composition of debris on beaches from Northeast Brazil, and Chiappone et al. (2005) on the impact of lost fishing gear on coral reefs in Florida, USA. A worldwide coverage was achieved by Browne et al. (2011) who determined the microplastics abundance (mainly from cloth fibres) at shorelines of 18 countries.

\subsubsection{Temporal Scale}

Citizen-science studies require a lot of organization. Accordingly, short-term studies are expected to be the most common among all citizen-science studies. Nevertheless, the time range of citizen-science studies vary from single events, up to a study of 27 years by van Franeker et al. (2011), who determined the abundance of ingested plastics by northern fulmars Fulmarus glacialis from the North Sea, as an indication of litter contamination. The majority of citizen-science studies $(63 \%)$ cover time periods ranging from less than 1-2 years, followed by studies between 5 and 10 years $(20 \%)$ (Table 16.3). Professional studies varied between single events up to a study on microplastics that compared recent samples with samples taken 40 years ago (Thompson et al. 2004). Interestingly, many professional studies were conducted only once, i.e. they spanned less than one year (53\%), whereas others ranged from 1 to 2 years $(10 \%)$ and 2 to 5 years $(10 \%)$, respectively. Three professional observational studies did not report the temporal scale of the investigation (Corcoran et al. 2009; Costa et al. 2010; Claessens et al. 2011) (Table 16.3).

\subsubsection{Regions Where Studies Have Been Done}

The problem of marine litter is widespread and has caused concern worldwide. However, global knowledge about marine litter is limited, because the majority of both citizen-science and professional studies on marine litter have been conducted in the northern hemisphere. Most citizen-science studies have been reported from Asia and South America (Fig. 16.3a). Professional studies have been conducted

Table 16.3 Comparison of the temporal scale of citizen-science $(\mathrm{N}=40)$ and professional studies $(\mathrm{N}=40)$

\begin{tabular}{l|l|l|l|l}
\hline \multirow{2}{*}{ No. of years } & \multicolumn{2}{l|}{ Citizen science } & \multicolumn{2}{l}{ Professional } \\
\cline { 2 - 5 } & No. & $\%$ & No. & $\%$ \\
\hline$<1$ & 12 & 30 & 21 & 52.5 \\
\hline $1-2$ & 13 & 32.5 & 4 & 10 \\
\hline$>2-5$ & 4 & 10 & 4 & 10 \\
\hline$>5-10$ & 8 & 20 & 2 & 5 \\
\hline$>10$ & 3 & 7.5 & 6 & 15 \\
\hline No information & - & 0 & 3 & 7.5 \\
\hline
\end{tabular}




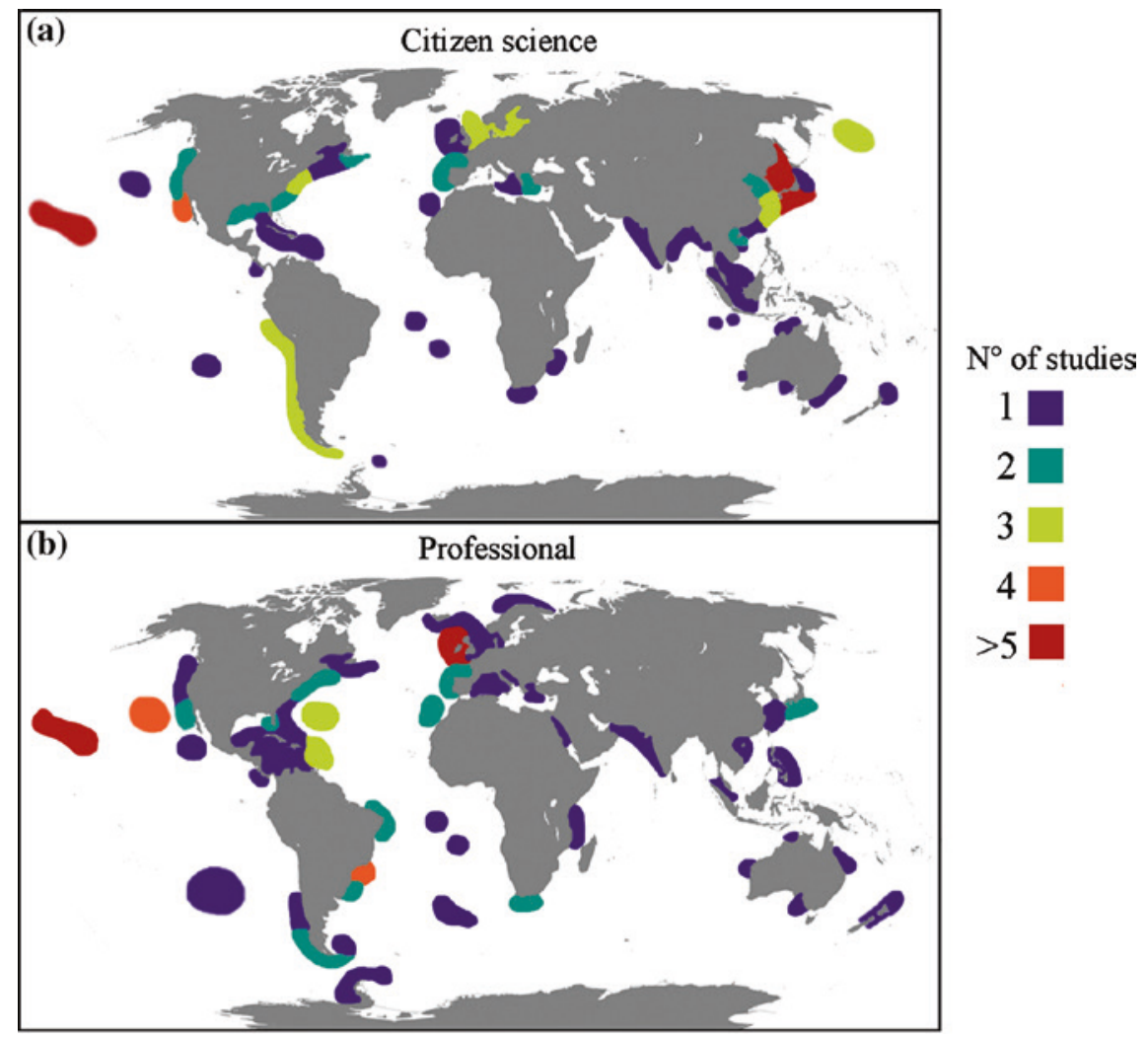

Fig. 16.3 World map with representation of the number of studies per ecoregion (limits of ecoregions after Spalding et al. 2007), for (a) citizen-science and (b) professional studies

mainly in Europe and the North Pacific Ocean (Hawaii and the North Pacific gyre) (Fig. 16.3b). This reveals a lack of information on coastal regions of the southern hemisphere, such as Africa and South America, except Chile. However, in the near future, the combination of citizen-science and professional studies can be the key to achieving global knowledge about litter sources and quantities, especially for regions of the world where this information is still needed. Therefore, citizen science studies could be a good approach to help filling the last missing gaps on the world map.

\subsection{Data Collection and Quality Control of Citizen-Science Studies}

A main concern of citizen-science studies is whether the collected data are reliable and comparable to professional studies. Four main aspects need to be considered in order to ensure or improve data quality: (1) preparation of easy and straightforward protocols, 
(2) training of volunteers, (3) in situ supervision by professional participation, and (4) validation of data and samples (modified from Bonney et al. 2009). Of the citizen-science studies on marine litter examined, $55 \%$ included at least one of these steps (e.g. Rosevelt et al. 2013; Anderson and Alford 2014; Gago et al. 2014).

\subsubsection{Preparation of Easy and Straight-Forward Protocols}

The studies that took measures to guarantee data quality, provided standardized protocols, guidelines and datasheets (e.g. Ribic 1998; Gago et al. 2014). In order to create clear protocols, some studies needed to adjust the sampling target to be easily identified by citizen scientists. For instance, Ribic et al. (2010) found that citizen scientists occasionally missed small pieces of debris (no specific size range was mentioned) in a monitoring program for beach litter. As a consequence of that observation, Hidalgo-Ruz and Thiel (2013) in a study focusing exclusively on small-plastic debris, decided to sample only items larger than $1 \mathrm{~mm}$, which can be identified by the naked eye after sieving of sand. Once the sampling target is determined, the marine litter items likely to be found by citizen scientists can be photographed and included in preparatory materials. Photographs of marine litter items were used in $15 \%$ of the studies (e.g. Moore et al. 2009; Anderson and Alford 2014).

\subsubsection{Training of Volunteers}

Data quality can also be improved by volunteer training (e.g. Storrier and McGlashan 2006; Smith et al. 2014). Indeed, $38 \%$ of the citizen science studies examined here included a degree of training or preparation of the volunteers. Training could consist of a one-hour classroom preparation (e.g. Smith et al. 2014) or a brief introduction in the field just before the sampling activity (e.g. Moore et al. 2009). For instance, a study on ghost fishing by derelict crab traps (Anderson and Alford 2014) was preceded by a training period. Furthermore, during one study year, participants were asked to take photos of every trap and to identify the organisms in the traps. These photos were later examined by professional scientists who confirmed that the data recorded for each trap were accurate.

\subsubsection{In Situ Supervision by Professionals}

Scientists and survey monitors participated in the sampling activity in $43 \%$ of the examined citizen-science studies. These professionals were in charge of assuring accuracy of debris classification, data recording and identification of missed/overlooked debris items (e.g. Ribic et al. 2011, 2012a). For example, in a study from South Korea on the impacts of marine debris on wildlife, experts from wildlife, 
nature and marine research institutes provided data quality assurance on a voluntary basis contributing pictures of dissections or autoradiography in order to demonstrate how animals were affected by the debris (Hong et al. 2013).

\subsubsection{Validation of Data and Samples}

Citizen-science studies can also incorporate a validation process in which the data gathered by volunteers are compared to data obtained by professional scientists. This comparative approach was applied by $18 \%$ of the studies, which evaluated the quality of the citizen-science data by re-counting the litter items, also using a microscope to differentiate between biological and synthetic litter (Rosevelt et al. 2013). For instance, Hidalgo-Ruz and Thiel (2013) recounted small plastic particles in samples that had been counted by citizen scientists. In one case, it was found that glass shards had been misidentified as small plastic debris. Elimination of samples with this kind of obvious error from the analysis can substantially improve data quality. According to Lindborg et al. (2012), citizen scientists can dissect and analyze seabird boluses with high accuracy resulting in measurements of contamination rates similar to those obtained by professional scientists. Validation can also be done by scientists analyzing photographs of samples taken by volunteers (Moore et al. 2009). Technological equipment can be used to generate complementary data. For instance, Seino et al. (2009) used high-frequency ocean radar, airplanes and balloons to take photographs of marine litter, which were used to complement data collected by volunteers. Data quality control can also entail the elimination of erroneous data. For instance, in a user survey on beach littering, Eastman et al. (2013) explicitly reported the data that were dismissed for further analyses. These data were related to mistaken, non-sensical and incomplete surveys, such as when children were too young to accurately complete the survey, or data were from locations with characteristics that differed from the main surveyed area (Eastman et al. 2013).

A remaining $45 \%$ of citizen-science studies had no data quality control. In certain studies, no specific validation step might be necessary because volunteers only gathered qualitative data during beach cleanup activities $(n=11)$ or citizens only participated in opportunistic sighting and sample collection of dead animals, bird boluses, pellets and drifter buoys found on beaches $(n=5)$. No data quality control was explicitly mentioned in the professional studies examined herein.

\subsection{Recommendations for Citizen-Science Projects on Marine Litter}

In order to carefully plan a citizen-science study, certain models for developing studies should be followed (Bonney et al. 2009). The research question should be easy to understand by participants and should incorporate strategies 
to motivate volunteers (Eastman et al. 2014). High levels of personal motivation, training procedures, and encouraging volunteers to describe any uncertainties to researchers resulted in improved accuracy achieved by citizen scientists (Lindborg et al. 2012). The time commitment of the participation of individuals and organizations should be respected. Accordingly, project leaders should concede ample time for the recruitment and training of volunteers. Sampling methods and data collection should be easy to manage with simple tools (e.g. transects, quadrats). Technology, such as smartphone applications and geo-referenced photos can be a novel tool to explore (e.g. Martin 2013). It is strongly recommended that a professional scientist demonstrates the tasks that citizen scientists will be performing in the field beforehand. Whenever possible, scientific surveys themselves should be supervised by scientists in order to ensure proper sampling and data collection. Participants should also be involved in the data evaluation and communication of results as a concluding activity, because this will enhance their commitment to the activity. Considering these recommendations, citizen scientists are capable to collect relevant data, even showing no significant difference with results gathered by experienced scientists (Thiel et al. 2014).

\subsection{Outlook and Conclusions}

The vast distribution of marine litter throughout the world requires extensive sampling efforts of research teams, and the available information is still limited to certain topics of research and regions of the world. In this respect, citizen-science projects have made important contributions to marine litter science. Collaborations with citizen scientists can be a useful approach to expand the understanding of marine litter in the world. Most studies have focused on the distribution and composition of marine litter, and beach cleanups are activities with the most active participation from citizen scientists.

Citizen science studies can cover a wide range of scales, from local to international range, single events to long-term multi-year projects. Through the use of citizen scientists, new research areas can be addressed in the future. Coastal marine litter may be monitored by citizen-science studies, which can also include other citizens related to the sea, such as local people, fishers, sport clubs and tourists. For instance, diver associations around the world can be trained to sample subtidal plastic debris, and new projects can be initiated with the help of sailing clubs, where long-distance travelers can survey floating marine debris by direct observation at sea, to study the distribution, composition and degradation of marine litter in the open ocean. Citizen scientists can help to determine local litter sources, thereby contributing to keeping coastal regions clean. Citizen-science projects can focus on interviewing mariners, coastal people and local governments, for the purpose of identifying ways to reduce marine litter deposition. 
With proper coordination, citizen science can include several other topics, such as interaction with biota and toxic effects. Nevertheless, a main concern of marine citizen science is to assure the quality of the collected data. In general, studies should include several steps to ensure data quality, including clear protocols, training of volunteers, participation of professional scientists, and revision of samples and data. If these considerations are taken into account, citizen scientists not only can help with investigating the problem of marine litter, but they can become key allies in solving the problem of marine litter.

Acknowledgments It seems ironic that most professional scientists studying marine litter have initially been trained in marine biology, microbiology, oceanography or related disciplines. By having redirected their research attention to the problem of marine litter, they have demonstrated that they are true citizens of the oceans! With their fascination for the sea, they join the thousands of enthusiastic citizens all over the world who have contributed to some of the research discussed herein. We thank all the schoolchildren and teachers who have participated in the citizen science program "Científicos de la Basura" and who continue to motivate us every day in this quest for a clean ocean. We are also grateful to two anonymous reviewers and to Annie Mejaes who did the final language check of the manuscript.

Open Access This chapter is distributed under the terms of the Creative Commons Attribution Noncommercial License, which permits any noncommercial use, distribution, and reproduction in any medium, provided the original author(s) and source are credited.

\section{References}

Anderson, J. A., \& Alford, A. B. (2014). Ghost fishing activity in derelict blue crab traps in Louisiana. Marine Pollution Bulletin, 79, 261-267.

Barnes, D. K. A. (2002). Biodiversity: Invasions by marine life on plastic debris. Nature, 416, 808-809.

Barnes, D. K. A., \& Milner, P. (2005). Drifting plastic and its consequences for sessile organism dispersal in the Atlantic Ocean. Marine Biology, 146, 815-825.

Barnes, D. K. A., Galgani, F., Thompson, R. C., \& Barlaz, M. (2009). Accumulation and fragmentation of plastic debris in global environments. Philosophical Transactions of the Royal Society B, 364, 985-1998.

Bjorndal, K. A., Bolten, A. B., \& Lagueux, C. J. (1994). Ingestion of marine debris by juvenile sea turtles in coastal Florida habitats. Marine Pollution Bulletin, 28, 154-158.

Boerger, C. M., Lattin, G. L., Moore, S. L., \& Moore, C. J. (2010). Plastic ingestion by planktivorous fishes in the North Pacific Central Gyre. Marine Pollution Bulletin, 60, 2275-2278.

Bonney, R., Cooper, C. B., Dickinson, J., Kelling, S., Phillips, T., Rosenberg, K. V., et al. (2009). Citizen science: A developing tool for expanding science knowledge and scientific literacy. BioScience, 59, 977-984.

Boren, L. J., Morrissey, M., Muller, C. G., \& Gemmell, N. J. (2006). Entanglement of New Zealand fur seals in man-made debris at Kaikoura, New Zealand. Marine Pollution Bulletin, $52,442-446$.

Bravo, M., Gallardo, M., Luna-Jorquera, G., Núñez, P., Vásquez, N., \& Thiel, M. (2009). Anthropogenic debris on beaches in the SE Pacific (Chile): Results from a national survey supported by volunteers. Marine Pollution Bulletin, 58, 1718-1726.

Browne, M. A., Dissanayake, A., Galloway, T. S., Lowe, D. M., \& Thompson, R. C. (2008). Ingested microscopic plastic translocates to the circulatory system of the mussel, Mytilus edulis (L.). Environmental Science and Technology, 42, 5026-5031. 
Browne, M. A., Galloway, T. S., \& Thompson, R. C. (2010). Spatial patterns of plastic debris along estuarine shorelines. Environmental Science and Technology, 44, 3404-3409.

Browne, M. A., Crump, P., Niven, S. J., Teuten, E., Tonkin, A., Galloway, T., et al. (2011). Accumulation of microplastic on shorelines woldwide: Sources and sinks. Environmental Science and Technology, 45, 9175-9179.

Carson, H. S. (2013). The incidence of plastic ingestion by fishes: From the prey's perspective. Marine Pollution Bulletin, 74, 170-174.

Carson, H. S., Lamson, M. R., Nakashima, D., Toloumu, D., Hafner, J., Maximenko, N., et al. (2013). Tracking the sources and sinks of local marine debris in Hawaii. Marine Environmental Research, 84, 76-83.

Chiappone, M., Dienes, H., Swanson, D. W., \& Miller, S. L. (2005). Impacts of lost fishing gear on coral reef sessile invertebrates in the Florida Keys National Marine Sanctuary. Biological Conservation, 121, 221-230.

Claereboudt, M. R. (2004). Shore litter along sandy beaches of the Gulf of Oman. Marine Pollution Bulletin, 49, 770-777.

Claessens, M., Meester, S. D., Landuyt, L. V., Clerck, K. D., \& Janssen, C. R. (2011). Occurrence and distribution of microplastics in marine sediments along the Belgian coast. Marine Pollution Bulletin, 62, 2199-2204.

Cole, M., Lindeque, P., Fileman, E., Halsband, C., Goodhead, R., Moger, J., et al. (2013). Microplastic ingestion by zooplankton. Environmental Science and Technology, 47, 6646-6655.

Corcoran, P. L., Biesinger, M. C., \& Grifi, M. (2009). Plastics and beaches: A degrading relationship. Marine Pollution Bulletin, 58, 80-84.

Costa, M. F., do Sul, J. A. I., Silva-Cavalcanti, J. S., Araújo, M. C. B., Spengler, Â., \& Tourinho, P. S. (2010). On the importance of size of plastic fragments and pellets on the strandline: a snapshot of a Brazilian beach. Environmental Monitoring and Assessment, 168, 299-304.

Dameron, O. J., Parke, M., Albins, M. A., \& Brainard, R. (2007). Marine debris accumulation in the Northwestern Hawaiian Islands: An examination of rates and processes. Marine Pollution Bulletin, 54, 423-433.

Davison, P., \& Asch, R. G. (2011). Plastic ingestion by mesopelagic fishes in the North Pacific Subtropical Gyre. Marine Ecology Progress Series, 432, 173-180.

Derraik, J. G. B. (2002). The pollution of the marine environment by plastic debris: A review. Marine Pollution Bulletin, 44, 842-852.

Eastman, L. B., Núñez, P., Crettier, B., \& Thiel, M. (2013). Identification of self-reported user behavior, education level, and preferences to reduce littering on beaches-A survey from the SE Pacific. Ocean and Coastal Management, 78, 18-24.

Eastman, L., Hidalgo-Ruz, V., Macaya-Caquilpán, V., Nuñez, P., \& Thiel, M. (2014). The potential for young citizen scientist projects: A case study of Chilean schoolchildren collecting data on marine litter. Coastal and Marine Management in Latin America14, 569-579.

Edyvane, K. S., Dalgetty, A., Hone, P. W., Higham, J. S., \& Wace, N. M. (2004). Long-term marine litter monitoring in the remote Great Australian Bight, South Australia. Marine Pollution Bulletin, 48, 1060-1075.

Endo, S., Takizawa, R., Okuda, K., Takada, H., Chiba, K., Kanehiro, H., et al. (2005). Concentration of polychlorinated biphenyls (PCBs) in beached resin pellets: Variability among individual particles and regional differences. Marine Pollution Bulletin, 50, 1103-1114.

Eriksen, M., Lebreton, L. C. M., Carson, H. S., Thiel, M., Moore, C. J., Borerro, J. C., et al. (2014). Plastic pollution in the world's oceans: More than 5 trillion plastic pieces weighing over 250,000 Tons afloat at sea. PLoS ONE, 9, e111913.

Fendall, L. S., \& Sewell, M. A. (2009). Contributing to marine pollution by washing your face: Microplastics in facial cleansers. Marine Pollution Bulletin, 58, 1225-1228.

Gago, J., Lahuerta, F., \& Antelo, P. (2014). Characteristics (abundance, type and origin) of beach litter on the Galician coast (NW Spain) from 2001 to 2010. Scientia Marina, 78, 125-134.

Galgani, F., Hanke, G., \& Maes, T. (2015). Global distribution, composition and abundance of marine litter. In M. Bergmann, L. Gutow \& M. Klages (Eds.), Marine anthropogenic litter (pp. 29-56). Springer: Berlin. 
Graham, E. R., \& Thompson, J. T. (2009). Deposit- and suspension-feeding sea cucumbers (Echinodermata) ingest plastic fragments. Journal of Experimental Marine Biology and Ecology, 368, 22-29.

Gregory, M. R. (1991). The hazards of persistent marine pollution: Drift plastics and conservation islands. Journal of the Royal Society of New Zealand, 21, 83-100.

Heskett, M., Takada, H., Yamashita, R., Yuyama, M., Ito, M., Geok, Y. B., et al. (2012). Measurement of persistent organic pollutants (POPs) in plastic resin pellets from remote islands: Toward establishment of background concentrations for International Pellet Watch. Marine Pollution Bulletin, 64, 445-448.

Hidalgo-Ruz, V., \& Thiel, M. (2013). Distribution and abundance of small plastic debris on beaches in the SE Pacific (Chile): A study supported by a citizen science project. Marine Environmental Research, 87, 12-18.

Hinojosa, I. A., \& Thiel, M. (2009). Floating marine debris in fjords, gulfs and channels of southern Chile. Marine Pollution Bulletin, 58, 341-350.

Hirai, H., Takada, H., Ogata, Y., Yamashita, R., Mizukawa, K., Saha, M., et al. (2011). Organic micropollutants in marine plastics debris from the open ocean and remote and urban beaches. Marine Pollution Bulletin, 62, 1683-1692.

Hong, S., Lee, J., Jang, Y. C., Kim, Y. J., Kim, H. J., Han, D., et al. (2013). Impacts of marine debris on wild animals in the coastal area of Korea. Marine Pollution Bulletin, 66, 117-124.

Hong, S., Lee, J., Kang, D., ChoI, H. W., \& Ko, S. H. (2014). Quantities, composition, and sources of beach debris in Korea from the results of nationwide monitoring. Marine Pollution Bulletin, 84, 27-34.

Jackson, N. L., Cerrato, M. L., \& Elliot, N. (1997). Geography and fieldwork at the secondary school level: An investigation of anthropogenic litter on an estuarine shoreline. Journal of Geography, 96, 301-306.

Jóźwiak, T. (2005). Tendencies in the numbers of beverage containers on the Polish coast in the decade from 1992 to 2001. Marine Pollution Bulletin, 50, 87-90.

Katsanevakis, S., \& Katsarou, A. (2004). Influences on the distribution of marine debris on the seafloor of shallow coastal areas in Greece (Eastern Mediterranean). Water, Air, and Soil Pollution, 159, 325-337.

Kiessling, T., Gutow, L., \& Thiel, M. (2015). Marine litter as a habitat and dispersal vector. In M. Bergmann, L. Gutow, \& M. Klages (Eds.), Marine anthropogenic litter (pp. 141-181). Springer: Berlin.

Kordella, S., Geraga, M., Papatheodorou, G., Fakiris, E., \& Mitropoulou, I. M. (2013). Litter composition and source contribution for 80 beaches in Greece, Eastern Mediterranean: A nationwide voluntary clean-up campaign. Aquatic Ecosystem Health and Management, 16, 111-118.

Kusui, T., \& Noda, M. (2003). International survey on the distribution of stranded and buried litter on beaches along the Sea of Japan. Marine Pollution Bulletin, 47, 175-179.

Laist, D. W. (1997). Impacts of marine debris: Entanglement of marine life in marine debris including a comprehensive list of species with entanglement and ingestion records. In J. M. Coe, \& D. B. Rogers (Eds.), Marine debris: sources, impacts, and solutions (pp. 99-139). New York: Springer.

Lattin, G. L., Moore, C. J., Zellers, A. F., Moore, S. L., \& Weisberg, S. B. (2004). A comparison of neustonic plastic and zooplankton at different depths near the southern California shore. Marine Pollution Bulletin, 49, 291-294.

Law, K. L., Morét-Ferguson, S., Maximenko, N. A., Proskurowski, G., Peacock, E. E., Hafner, J., et al. (2010). Plastic accumulation in the North Atlantic subtropical gyre. Science, 329, $1185-1188$.

Lazar, B., \& Gračan, R. (2011). Ingestion of marine debris by loggerhead sea turtles, Caretta caretta, in the Adriatic Sea. Marine Pollution Bulletin, 62, 43-47.

Lindborg, V. A., Ledbetter, J. F., Walat, J. M., \& Moffett, C. (2012). Plastic consumption and diet of Glaucous-winged gulls (Larus glaucescens). Marine Pollution Bulletin, 64, 2351-2356.

Löder, M. G. J., \& Gerdts, G. (2015). Methodology used for the detection and identification of microplastics-A critical appraisal. In M. Bergmann, L. Gutow, \& M. Klages (Eds.), Marine anthropogenic litter (pp. 201-227). Springer: Berlin. 
Martin, J. M. (2013). Marine debris removal: One year of effort by the Georgia Sea turtle-centermarine debris initiative. Marine Pollution Bulletin, 74, 165-169.

Martinez, E., Maamaatuaiahutapu, K., \& Taillandier, V. (2009). Floating marine debris surface drift: Convergence and accumulation toward the South Pacific subtropical gyre. Marine Pollution Bulletin, 58, 1347-1355.

Mascarenhas, R., Santos, R., \& Zeppelini, D. (2004). Debris ingestion by sea turtle in Paraíba, Brazil. Marine Pollution Bulletin, 49, 354-355.

Masó, M., Garcés, E., Pagès, F., \& Camp, J. (2003). Drifting plastic debris as a potential vector for dispersing Harmful Algal Bloom (HAB) species. Scientia Marina, 67, 107-111.

Maximenko, N., Hafner, J., \& Niiler, P. (2012). Pathways of marine debris derived from trajectories of Lagrangian drifters. Marine Pollution Bulletin, 65, 51-62.

McDermid, K. J., \& McMullen, T. L. (2004). Quantitative analysis of small-plastic debris on beaches in the Hawaiian archipelago. Marine Pollution Bulletin, 48, 790-794.

Moore, S. L., Gregorio, D., Carreon, M., Weisberg, S. B., \& Leecaster, M. K. (2001). Composition and distribution of beach debris in Orange County, California. Marine Pollution Bulletin, 42, 241-245.

Moore, E., Lyday, S., Roletto, J., Litle, K., Parrish, J. K., Nevins, H., et al. (2009). Entanglements of marine mammals and seabirds in central California and the north-west coast of the United States 2001-2005. Marine Pollution Bulletin, 58, 1045-1051.

Morét-Ferguson, S., Law, K. L., Proskurowski, G., Murphy, E. K., Peacock, E. E., \& Reddy, C. M. (2010). The size, mass, and composition of plastic debris in the western North Atlantic Ocean. Marine Pollution Bulletin, 60, 1873-1878.

Morishige, C., Donohue, M. J., Flint, E., Swenson, C., \& Woolaway, C. (2007). Factors affecting marine debris deposition at French Frigate Shoals, northwestern Hawaiian islands marine national monument, 1990-2006. Marine Pollution Bulletin, 54, 1162-1169.

Murray, F., \& Cowie, P. R. (2011). Plastic contamination in the decapod crustacean Nephrops norvegicus (Linnaeus, 1758). Marine Pollution Bulletin, 62, 1207-1217.

Ng, K. L., \& Obbard, J. P. (2006). Prevalence of microplastics in Singapore's coastal marine environment. Marine Pollution Bulletin, 52, 761-767.

Ogata, Y., Takada, H., Mizukawa, K., Hirai, H., Iwasa, S., Endo, S., et al. (2009). International pellet watch: Global monitoring of persistent organic pollutants (POPs) in coastal waters. 1. Initial phase data on PCBs, DDTs, and HCHs. Marine Pollution Bulletin, 58, 1437-1446.

Oigman-Pszczol, S. S., \& Creed, J. C. (2007). Quantification and classification of marine litter on beaches along Armação dos Búzios, Rio de Janeiro, Brazil. Journal of Coastal Research, 23, $421-428$.

Page, B., McKenzie, J., McIntosh, R., Baylis, A., Morrissey, A., Calvert, N., et al. (2004). Entanglement of Australian sea lions and New Zealand fur seals in lost fishing gear and other marine debris before and after Government and industry attempts to reduce the problem. Marine Pollution Bulletin, 49, 33-42.

Pichel, W. G., Churnside, J. H., Veenstra, T. S., Foley, D. G., Friedman, K. S., Brainard, R. E., et al. (2007). Marine debris collects within the North Pacific subtropical convergence zone. Marine Pollution Bulletin, 54, 1207-1211.

Reddy, M. S., Basha, S., Adimurthy, S., \& Ramachandraiah, G. (2006). Description of the small plastics fragments in marine sediments along the Alang-Sosiya ship-breaking yard, India. Estuarine, Coastal and Shelf Science, 68, 656-660.

Ribic, C. A. (1998). Use of indicator items to monitor marine debris on a New Jersey beach from 1991 to 1996. Marine Pollution Bulletin, 36, 887-891.

Ribic, C. A., Sheavly, S. B., Rugg, D. J., \& Erdmann, E. S. (2010). Trends and drivers of marine debris on the Atlantic coast of the United States 1997-2007. Marine Pollution Bulletin, 60, $1231-1242$.

Ribic, C. A., Sheavly, S. B., \& Rugg, D. J. (2011). Trends in marine debris in the US Caribbean and the Gulf of Mexico 1996-2003. Journal of Integrated Coastal Zone Management, 11, 7-19.

Ribic, C. A., Sheavly, S. B., Rugg, D. J., \& Erdmann, E. S. (2012a). Trends in marine debris along the US Pacific Coast and Hawai'i 1998-2007. Marine Pollution Bulletin, 64, 994-1004. 
Ribic, C. A., Sheavly, S. B., \& Klavitter, J. (2012b). Baseline for beached marine debris on Sand Island, Midway Atoll. Marine Pollution Bulletin, 64, 1726-1729.

Rios, L. M., Moore, C., \& Jones, P. R. (2007). Persistent organic pollutants carried by synthetic polymers in the ocean environment. Marine Pollution Bulletin, 54, 1230-1237.

Rios, L. M., Jones, P. R., Moore, C., \& Narayan, U. V. (2010). Quantitation of persistent organic pollutants adsorbed on plastic debris from the Northern Pacific Gyre's "eastern garbage patch". Journal of Environmental Monitoring, 12, 2226-2236.

Rosevelt, C., Los Huertos, M., Garza, C., \& Nevins, H. M. (2013). Marine debris in central California: Quantifying type and abundance of beach litter in Monterey Bay, CA. Marine Pollution Bulletin, 71, 299-306.

Ross, J. B., Parker, R., \& Strickland, M. (1991). A survey of shoreline litter in Halifax Harbour 1989. Marine Pollution Bulletin, 22, 245-248.

Ryan, P. G. (2008). Seabirds indicate changes in the composition of plastic litter in the Atlantic and south-western Indian Oceans. Marine Pollution Bulletin, 56, 1406-1409.

Ryan, P. G., Moore, C. J., van Franeker, J. A., \& Moloney, C. L. (2009). Monitoring the abundance of plastic debris in the marine environment. Philosophical Transactions of the Royal Society of London B, 364, 1999-2012.

Santos, I. R., Friedrich, A. C., Wallner-Kersanach, M., \& Fillmann, G. (2005). Influence of socio-economic characteristics of beach users on litter generation. Ocean and Coastal Management, 48, 742-752.

Santos, I. R., Friedrich, A. C., \& Ivar do Sul, J. A. (2009). Marine debris contamination along undeveloped tropical beaches from northeast Brazil. Environmental Monitoring and Assessment, 148, 455-462.

Seino, S., Kojima, A., Hinata, H., Magome, S. N., \& Isobe, A. (2009). Multi-sectoral research on East China Sea beach litter based on oceanographic methodology and local knowledge. Journal of Coastal Research, 56, 1289-1292.

Shimizu, T., Nakai, J., Nakajima, K., Kozai, N., Takahashi, G., Matsumoto, M., et al. (2008). Seasonal variations in coastal debris on Awaji Island, Japan. Marine Pollution Bulletin, 57, 182-186.

Smith, S. D., \& Edgar, R. J. (2014). Documenting the density of subtidal marine debris across multiple marine and coastal habitats. PLoS ONE, 9, e94593.

Smith, S. D., Gillies, C. L., \& Shortland-Jones, H. (2014). Patterns of marine debris distribution on the beaches of Rottnest Island, Western Australia. Marine Pollution Bulletin, 88, 188-193.

Spalding, M. D., Fox, H. E., Allen, G. R., Davidson, N., Ferdaña, Z. A., Finlayson, M., et al. (2007). Marine ecoregions of the world: A bioregionalization of coastal and shelf areas. BioScience, 57, 573-583.

Storrier, K. L., \& McGlashan, D. J. (2006). Development and management of a coastal litter campaign: The voluntary coastal partnership approach. Marine Policy, 30, 189-196.

Storrier, K. L., McGlashan, D. J., Bonellie, S., \& Velander, K. (2007). Beach litter deposition at a selection of beaches in the Firth of Forth, Scotland. Journal of Coastal Research, 23, 813-822.

Teuten, E. L., Rowland, S. J., Galloway, T. S., \& Thompson, R. C. (2007). Potential for plastics to transport hydrophobic contaminants. Environmental Science and Technology, 41, 7759-7764.

Thiel, M., Penna-Díaz, M. A., Luna-Jorquera, G., Sala, S., Sellanes, J., \& Stotz, W. (2014). Citizen scientists and marine research: Volunteer participants, their contributions and projection for the future. Oceanography and Marine Biology: An Annual Review, 52, 257-314.

Thompson, R. C., Olsen, Y., Mitchell, R. P., Davis, A., Rowland, S. J., John, A. W., et al. (2004). Lost at sea: where is all the plastic? Science, 304, 838.

Tourinho, P. S., Ivar do Sul, J. A., \& Fillmann, G. (2010). Is marine debris ingestion still a problem for the coastal marine biota of southern Brazil? Marine Pollution Bulletin, 60, 396-401.

van Franeker, J. A., Blaize, C., Danielsen, J., Fairclough, K., Gollan, J., Guse, N., et al. (2011). Monitoring plastic ingestion by the northern fulmar Fulmarus glacialis in the North Sea. Environmental Pollution, 159, 2609-2615. 
Whiting, S. D. (1998). Types and sources of marine debris in Fog Bay, Northern Australia. Marine Pollution Bulletin, 36, 904-910.

Young, L. C., Vanderlip, C., Duffy, D. C., Afanasyev, V., \& Shaffer, S. A. (2009). Bringing home the trash: Do colony-based differences in foraging distribution lead to increased plastic ingestion in Laysan albatrosses? PLoS ONE, 4, e7623.

\section{Appendices}

\section{Appendix 1: Citizen-Science and Professional Studies on Marine Litter}

\begin{tabular}{|c|c|c|}
\hline Reference & Topic & Locations \\
\hline \multicolumn{3}{|l|}{ Citizen science studies } \\
\hline Anderson and Alford (2014) & Interaction with biota & Lousiana, United States \\
\hline Bjorndal et al. (1994) & Interaction with biota & Florida, United States \\
\hline Bravo et al. (2009) & Distribution and composition & Chilean coast \\
\hline Carson (2013) & Interaction with biota & Hawaii an islands \\
\hline Carson et al. (2013) & Distribution and composition & Hawaii an islands \\
\hline Eastman et al. (2013) & Social aspects & Chilean coast \\
\hline Edyvane et al. (2004) & Distribution and composition & Anxious Bay, South Australia \\
\hline Endo et al. (2005) & Toxic effects & Tokyo, Japan \\
\hline Gago et al. (2014) & Distribution and composition & Galicia, Spain \\
\hline Gregory (1991) & Distribution and composition & Hauraki Bay, New Zealand \\
\hline Heskett et al. (2012) & Toxic effects & $\begin{array}{l}\text { Canary, Oahu, Hawaii, } \\
\text { Barbados, Cocos and St. } \\
\text { Helena Islands }\end{array}$ \\
\hline Hidalgo-Ruz and Thiel (2013) & Distribution and composition & Continental Chile, Easter Island \\
\hline Hirai et al. (2011) & Toxic effects & North Pacific \\
\hline Hong et al. (2013) & Interaction with biota & Korea \\
\hline Hong et al. (2014) & Distribution and composition & Korea \\
\hline Jackson et al. (1997) & Distribution and composition & New Jersey, United States \\
\hline Jóźwiak (2005) & Distribution and composition & Poland \\
\hline Kordella et al. (2013) & Distribution and composition & Eastern Mediterranean \\
\hline Kusui and Noda (2003) & Distribution and composition & Japan, Russia \\
\hline Lindborg et al. (2012) & Interaction with biota & Washington, United States \\
\hline Martin (2013) & Distribution and composition & Jekyll Island \\
\hline Moore et al. (2001) & Distribution and composition & California, United States \\
\hline Moore et al. (2009) & Interaction with biota & West coast, United States \\
\hline Morishige et al. (2007) & Transport & Hawaii an islands \\
\hline Ogata et al. (2009) & Toxic effects & Global \\
\hline Ribic (1998) & Distribution and composition & New Jersey, United States \\
\hline Ribic et al. (2010) & Distribution and composition & East coast, United States \\
\hline Ribic et al. (2011) & Distribution and composition & Gulf of Mexico \\
\hline
\end{tabular}


(continued)

\begin{tabular}{|c|c|c|}
\hline Reference & Topic & Locations \\
\hline Ribic et al. (2012a) & Distribution and composition & $\begin{array}{l}\text { West coast, United States, } \\
\text { Hawaii }\end{array}$ \\
\hline Ribic et al. (201b) & Distribution and composition & Midway Atoll \\
\hline Rosevelt et al. (2013) & Distribution and composition & California, United States \\
\hline Ross et al. (1991) & Distribution and composition & Nova Scotia, Canada \\
\hline Seino et al. (2009) & Distribution and composition & East China Sea \\
\hline Shimizu et al. (2008) & Distribution and composition & Awaji Island, Japan \\
\hline Smith and Edgar (2014) & Distribution and composition & Australia \\
\hline Smith et al. (2014) & Distribution and composition & Western Australia \\
\hline Storrier and McGlashan (2006) & Distribution and composition & Forth Estuary, United Kingdom \\
\hline Storrier et al. (2007) & Distribution and composition & Forth Estuary, United Kingdom \\
\hline Van Franeker et al. (2011) & Interaction with biota & North Sea \\
\hline Whiting (1998) & Distribution and composition & Australia \\
\hline \multicolumn{3}{|l|}{ Professional studies } \\
\hline Barnes and Milner (2005) & Interaction with biota & Atlantic Ocean \\
\hline Boerger et al. (2010) & Interaction with biota & North Pacific oceanic gyre \\
\hline Boren et al. (2006) & Interaction with biota & Kaikoura, New Zealand \\
\hline Browne et al. (2008) & Interaction with biota & Cornwall, United Kingdom \\
\hline Browne et al. (2010) & Distribution and composition & $\begin{array}{l}\text { Tamar Estuary, United } \\
\text { Kingdom }\end{array}$ \\
\hline Browne et al. (2011) & Distribution and composition & Global \\
\hline Chiappone et al. (2005) & Interaction with biota & Florida, United States \\
\hline Claereboudt (2004) & Distribution and composition & Gulf of Oman \\
\hline Claessens et al. (2011) & Distribution and composition & Belgium \\
\hline Corcoran et al. (2009) & Degradation & Kauai Island, Hawaii \\
\hline Costa et al. (2010) & Distribution and composition & Northeast Brazil \\
\hline Dameron et al. (2007) & Distribution and composition & Hawaiian Islands \\
\hline Davison and Asch (2011) & Interaction with biota & North Pacific gyre \\
\hline Fendall and Sewell (2009) & Distribution and composition & Auckland, New Zealand \\
\hline Graham and Thompson (2009) & Interaction with biota & Florida, Maine, United States \\
\hline Hinojosa and Thiel (2009) & Distribution and composition & Fjords, Southern Chile \\
\hline $\begin{array}{l}\text { Katsanevakis and Katsarou } \\
\text { (2004) }\end{array}$ & Distribution and composition & Greece \\
\hline Lattin et al. 2004 & Distribution and composition & California, United States \\
\hline Law et al. (2010) & Transport & Atlantic Ocean, Caribbean sea \\
\hline Lazar and Gracan (2011) & Interaction with biota & Adriatic Sea \\
\hline Martinez et al. (2009) & Transport & South Pacific gyre \\
\hline Mascarenhas et al. (2004) & Interaction with biota & Paraiba, Brazil \\
\hline Maximenko et al. (2012) & Transport & Global \\
\hline $\begin{array}{l}\text { McDermid and McMullen } \\
\text { (2004) }\end{array}$ & Distribution and composition & Hawaii an islands \\
\hline
\end{tabular}


(continued)

\begin{tabular}{l|l|l}
\hline Reference & Topic & Locations \\
\hline Morét-Ferguson et al. (2010) & Distribution and composition & North Atlantic Ocean \\
\hline Murray and Cowie (2011) & Interaction with biota & Clyde Sea, United Kingdom \\
\hline Ng and Obbard (2006) & Distribution and composition & Singapore \\
\hline $\begin{array}{l}\text { Oigman-Pszczol and Creed } \\
\text { (2007) }\end{array}$ & Distribution and composition & Rio de Janeiro, Brazil \\
\hline Page et al. (2004) & Interaction with biota & Australia \\
\hline Pichel et al. (2007) & Distribution and composition & North Pacific gyre \\
\hline Reddy et al. (2006) & Distribution and composition & India \\
\hline Rios et al. (2007) & Toxic effects & North Pacific gyre \\
\hline Rios et al. (2010) & Toxic effects & North Pacific gyre \\
\hline Ryan (2008) & Interaction with biota & $\begin{array}{l}\text { Atlantic, southwestern Indian } \\
\text { Oceans }\end{array}$ \\
\hline Santos et al. (2005) & Social aspects & Rio Grande, Brazil \\
\hline Santos et al. (2009) & Distribution and composition & Brazil \\
\hline Teuten et al. (2007) & Toxic effects & United Kingdom \\
\hline Thompson et al. (2004) & Distribution and composition & Plymouth, United Kingdom \\
\hline Tourinho et al. (2010) & Interaction with biota & Brazil \\
\hline Young et al. (2009) & Interaction with biota & North Pacific Ocean \\
\hline & &
\end{tabular}

